Because of the wide dissemination of these insensitive strains the dosage of penicillin has been progressively increased in recent years. While 300,000 units of procaine penicillin gave excellent cure rates in the early 1950 s, today doses of 1-2 mega units are more often given. It is agreed that high and persisting blood levels should be aimed at and that slowrelease preparations are unsuitable. G. D. Morrison and his colleagues $^{8}$ treated 280 men with uncomplicated gonorrhoea with a single injection of 2.4 mega units of aqueous procaine penicillin. There were 18 recurrences during the first two weeks after treatment, 6 of which were thought to be reinfections. These results were slightly better than those with a dosage of 1.2 mega units of the same preparation. Of 238 men so treated, 19 had recurrences within 14 days, 7 of which were classed as reinfections. Unfortunately no sensitivity studies were made during these surveys.

Penicillin is held by most clinicians still to be the drug of choice for treating gonorrhoea in Britain. Now that a considerable proportion of strains are insensitive in vitro, its position is being challenged. High and prolonged blood levels can be attained by giving probenecid with penicillin to delay its excretion, and this method has given good results in refractory cases. But whether the gonococcus will stay within its bounds of resistance is uncertain, as strains of greater resistance have been found in the Far East. Fortunately we are not wholly dependent on penicillin. Streptomycin, formerly a good alternative, is now of little value because penicillin-insensitive strains are almost all completely resistant to it. Tetracycline and kanamycin are satisfactory alternatives, though clinical failures are thought to be becoming commoner with the former. G. W. Csonka and G. J. Knight $^{9}$ have found that the combination of a sulphonamide and trimethoprim gave a cure rate of $89-93 \%$ and was also effective in a small group of patients who had failed to respond to penicillin. Treatment was spread over four days and was given by mouth, which is a disadvantage. Despite this drawback, it seems a most promising approach, and further work on variations of this combination of agents is desirable.

Treatment for gonorrhoea has to be given when the patient first attends, before the result of sensitivity tests is available. These are necessary investigations, and the susceptibility of the gonococcus to the agents in general use should be monitored to gain early warning of changes in its behaviour so that adjustments in treatment can be made.

\section{How Relevant is Present Cancer Research?}

This question must be in the minds of some readers of the 46th Annual Report of the British Empire Cancer Campaign for Research ${ }^{1}$ published this week. Some of the problems that research workers set themselves to solve by experiment seem remote from those of the patient who has got cancer or the person who seeks to avoid it. Part of the difficulty is one of communication. Many research projects are of longer duration than the 12 months covered by this report, so that readers may have to look at earlier reports for explanations of the relevance of the projects to human cancer. Moreover, since many of the more direct approaches to solving problems of human cancer have been explored already, in general more basic approaches are now called for. Much of the use of animals in experiments, including some of the simplest organisms, stems from the need to study effects under controlled conditions that carry the least risk of interference by possible biological variables.

The main branches of cancer research are summarized by the four words: diagnosis, treatment, causation, and prevention. One may wonder whether the campaign is devoting too much of its money to certain aspects of radiotherapeutic research, in which there appears to be considerable duplication of effort, and to research in radiation chemistry and biology, from which little of direct benefit to patients seems to be emerging.

Clinical evaluation of $\mathbf{L}$-asparaginase in the treatment of malignant disease other than acute leukaemia has been hampered by an inadequate supply of endotoxin-free enzyme. The survey by Sir Ernst Chain and his colleagues at Imperial College, London, of some 600 strains of bacteria for L-asparaginase production, and their discovery of some 60 highly productive strains, could improve this situation.

Various forms of immunotherapy, usually in combination with chemotherapy or surgery, have received some attention both experimentally and clinically. Work on it has recently been reviewed in these columns. ${ }^{2}{ }^{3}$ According to $S$. Denham and her colleagues at the Institute of Cancer Research four lymphoblasts from a lymph node specifically stimulated by the injection of killed lymphoma cells are needed to kill one living tumour cell of the type injected. This is in line with G. Hamilton Fairley's general conclusion" that " attempts at immunotherapy in patients with advanced disease are doomed to disappointment." H. E. M. Kay and others at the same institute report that non-specific stimulation of the reticuloendothelial system by biweekly injections of Bordetella pertussis prolongs remissions in patients with acute leukaemia.

"Early diagnosis" does not necessarily mean a greatly improved prognosis. For instance, cytological examination of the urine for malignant cells may lead to the effective treatment of a carcinoma of the bladder, but, as J. Swinney, of Newcastle upon Tyne, points out, such a carcinoma often arises out of a generally abnormal and unstable epithelium from which new neoplasms may emerge at any time. On the other hand, the computerized study of histopathological features of white lesions of the oral mucosa by R. B. Lucas and I. R. H. Kramer at the Royal Dental Hospital in London may, if it pinpoints those features associated with premalignancy, lead to benefit. For in this case there is at least some knowledge of how to reduce the risk of malignant change by improving oral hygiene.

Most surgeons will continue to put most store by their own clinical judgement in relation to the differential diagnosis between benign and malignant lumps in the breast. In a series of 410 cases that presented with a lump in one breast, K. D. Patil and K. Lloyd Williams, of Bath, report that $93 \%$ of the carcinomas were detectable by thermography but that $7 \%$ gave false negatives. By contrast, $9 \%$ of benign tumours gave false positive results. Improvement in the sensitivity of thermographic methods could result from the attempts of C. H. Jones and Janet W. Draper at the Institute of Cancer Research to characterize the effects of variables such as age, hormonal status, and mammary asymmetry. Reports from other countries have already indicated the value of screening for breast cancer among the general population. Experience

\footnotetext{
- British Empire Cancer Campaign for Research: Forty-Sixth Annual Report Covering the Year 1968. London. 1969.

Fairley, G. H., British Medical fournal, 1969, 2, 467.

3 British Medical fournal, 1969, 2, 461.

- See British Medical fournal, 1969, 1, 589.
} 
at King's College Hospital is similar. Five cases of cancer, four in an early stage 1, were found by the clinical examination of the breasts of 654 women in a London practice. Screening by the cervical smear test is still one of the most worth-while forms of early diagnosis, for two reasons: firstly, lesions that are truly early or even precancerous can be detected, and, secondly, unlike the bladder, the whole of the affected tissue can be removed without serious consequences. A report from the Exeter Clinic of the Family Planning Association indicates no excess of abnormal nuclei or malignant appearances in the cells of the cervix in women taking oral contraceptives in comparison with women wearing an intra-uterine contraceptive device.

Many of the experimental studies concern chemical agents that are not present in the normal human environment. Of the few that could lead to knowledge of how to prevent human cancer one may mention the attempts of R. A. M. Case to find safer alternatives to carcinogenic aromatic amines in certain routine laboratory tests-for example, the use of benzidine for the detection of blood in stools. An effort by C. E. Searle to remove carcinogenic chemicals of the same and other types from school laboratories in the City of Birmingham is surely one that should be matched in every education department in the country. Though cancer of the colon is one of the commoner forms of neoplasia in both men and women, and some attention is being paid to its earlier diagnosis and treatment, ${ }^{4}$ the only study directly aimed at discovering its causes is that of R. E. O. Williams at St. Mary's Hospital. He reports that the faeces of English people living on mixed diets contain more anaerobic Bacteroides, fewer enterococci and anaerobic Sarcinae, and significantly more neutral and acid steroids than the faeces of Ugandans living on a mainly vegetable diet and enjoying a lower risk of developing bowel cancer.

There seems to be rather a paucity of virological research. And why are so few studies concerned with the commonest type of cancer in men-namely, cancer of the bronchus? Nevertheless, the latest report gives plenty of evidence of imaginative work-indeed, perhaps more than in previous years.

\section{Fair Inquiry}

Some two and a half years ago the Monopolies Commission, on the instruction of the President of the Board of Trade, turned its attention to restrictive practices in the professions. Whether a body accustomed to investigate and pass judgement on trade practices is equally well equipped to examine the affairs of the professions remains to be seen. But certainly professional conduct, some of it stemming from traditional ethical principles, is legitimately a subject of public concern. Indeed its main purpose is to protect the public from abuse.

The medical profession is merely one of a number that are now objects of the commission's scrutiny, for it would seem that the nature of what professions characteristically offer in their services is being examined rather than the specific practices of each profession in turn, though these must be

British Medical fournal, 1967, 1, 376.

British Medical fournal, 1967, 4, 496.

British Medical fournal Supplement, 1968, 2, 42.

' British Medical fournal Supplement, 1968, 2, 38. looked at if generally valid inferences are to be drawn about their relevance to the public interest. At least this would seem to follow from the wide terms of reference guiding the commission and the variety of professions from which it is obtaining evidence in the course of this particular inquiry. However that may be, a report from the commission based on inadequate evidence or an incomplete understanding of the reasons for some professional procedure could be damaging to the reputation of any one of the professions as well as to the protection the public has through that procedure. Nor would such confusion enhance the commission's own reputation for fair and impartial inquiry in the public interest. Yet in refusing to follow its customary procedure and declining to hear oral evidence, despite a formal request from some of the professional organizations to do so, the commission is running a risk of reaching conclusions that may be unjust or at best irrelevant.

The commission's inquiry is into practices that are restrictive of entry into a profession, fees charged, rendering of services by persons in partnership, the manner in which services are supplied, the carrying on of another business, and advertising. ${ }^{1}$ In other words, it can look into and form conclusions on most aspects of professional life, and an initial restriction on the commission itself that it should not report on practices expressly authorized by any enactment or royal charter was largely removed some months after the inquiry began. ${ }^{2}$ Both the General Medical Council ${ }^{3}$ and the British Medical Association ${ }^{4}$ have submitted written evidence to the commission, as have professional bodies representing (among others) dentists, engineers, barristers, and surveyors.

Concerned as it has for so long been to protect the public from quacks and unscrupulous practitioners, the medical profession described in its evidence such " restrictive practices" as examinations to gain entry to the profession; ethical prohibitions on a variety of practices, such as advertising; and the rules that should guide a doctor to satisfy himself that a patient who comes to him for treatment is not already in the care of another doctor. These and the many other traditional features of professional life that have an element of restriction in them are perfectly fit subjects for inquiry, but the misinterpretation to which they are often seen to be liable is evidence enough that they need proper explanation to people who may be unfamiliar with their purpose-namely, to prevent unqualified or dishonest people from deceiving the public. It would be unfortunate if such an influential body as the Monopolies Commission was to reach conclusions without hearing the full evidence on exceedingly complex issues and thus run the risk of harming the delicate personal relationships between doctors and their patients.

\section{Delivery after Caesarean Section}

An estimated 254,540 caesarean sections were performed in England and Wales in the ten-year period 1957-66. ${ }^{1}$ The number of deaths " associated with but not necessarily due to caesarean section" investigated in the Confidential Enquiry into Maternal Deaths during the same period was 488 , giving a mortality rate of about $0 \cdot 2 \%$, approximately ten times the maternal mortality for all deliveries.

E. Holland ${ }^{2}$ recorded a $4 \%$ incidence of scar rupture and a $4 \%$ maternal mortality in subsequent pregnancy after 